\title{
Hylomorphic Animalism, Emergentism, and the Challenge of the New Mechanist Philosophy of Neuroscience
}

\author{
DANIEL D. DE HAAN \\ TWCF Fellow, Faculty of Divinity \& Department of Psychology, \\ University of Cambridge \\ daniel.d.dehaan@gmail.com
}

\begin{abstract}
This article, the first of a two-part essay, presents an account of Aristotelian hylomorphic animalism that engages with recent work on neuroscience and philosophy of mind. I show that Aristotelian hylomorphic animalism is compatible with the new mechanist approach to neuroscience and psychology, but that it is incompatible with strong emergentism in the philosophy of mind. I begin with the basic claims of Aristotelian hylomorphic animalism and focus on its understanding of psychological powers embodied in the nervous system. Next, I introduce the new mechanist approach to neuroscience and psychology and illustrate how it can enrich the more abstract ontological framework of Aristotelian hylomorphic animalism. In the third section of this article I establish in detail the many ways Aristotelian hylomorphic animalism is incompatible with strong emergentism in the philosophy of mind. Based on these fundamental differences I show why a criticism leveled against emergentism by the new mechanist philosophy does not hamper my proposed rapprochement between hylomorphism and the new mechanist philosophy. This conclusion, however, leaves untouched the problem I address in the second article, namely, is the new mechanist philosophy compatible with Aristotelian philosophical anthropology's contention that intellectual operations are immaterial and interact with the psychosomatic operations of the rational animal?
\end{abstract}

Keywords: Hylomorphism; Animalism; New Mechanist Philosophy; Neuroscience; Psychology; Philosophical Anthropology; Aristotelianism; Thomas Aquinas; Emergentism. 


\section{Abbreviations for the works of St. Thomas Aquinas}

De Pot Quaestiones disputatae de potentia

In DA Sentencia libri De anima

SCG Summa contra gentiles

ST Summa theologiae

There are numerous challenges that confront the prospects of a contemporary Aristotelian or Thomist philosophical anthropology. This two-part essay tackles one of those challenges head on. I present a speculative framework for characterizing the integrative interaction of immaterial intellectual operations with other psychological operations that are embodied in the nervous system. Why might this interaction be a problem?

Thomas Aquinas's account of Neo-Aristotelian hylomorphism presents an ontology of natural substances and their attributes. This hylomorphic ontology of natural things includes inanimate elements and mixts, as well as living beings such as plants and animals. Human persons complicate Neo-Aristotelian hylomorphism. This is because, medieval Neo-Aristotelians, like Aquinas, argued that the unique rational and intellectual operations of humans, which evince that they are persons, set them apart from other hylomorphic animals that are constituted from an animating sensory soul that is the substantial form of an organic material body. These intellectual operations transcend the conditions of matter and are grounded in the immaterial rational soul of the human person. The difficulty is that the intellectual nature of the rational soul and its immateriality seem to be incompatible with the ontology of hylomorphic animalism (HMA) and its account of the soul as the substantial form of a material body. Aquinas and other scholastics proposed a variety of unified and eclectic solutions to this tension, and Thomists up to the present continue to defend, develop, and elucidate Aquinas's approach to this problem. For the sake of simplicity, I call this latter position Thomist hylomorphic personalism (THP).

This essay contributes to these Thomist efforts to resolve certain apparent tensions in THP that concern the interaction of the human person's immaterial intellectual or noetic operations with the psychosomatic sensory 
operations that are constituted from the formal organization of the nervous system. Accordingly, I take for granted a number of contentious philosophical and scientific claims about human persons and their powers that these interaction problems presuppose. This first article sets up the background to the interaction problem for THP; in the second article, I address the problem of noetic and psychosomatic interaction for THP.

This first article commences with the basic claims of Neo-Aristotelian hylomorphic animalism and its account of embodied psychological powers and operations (§I). I then illustrate how hylomorphic animalism is enriched by the new mechanist philosophy's approach to biology, neuroscience, and psychology (§II). The rest of this two-part essay is dedicated to establishing the compatibility of a Thomist hylomorphism with empirical psychology and neuroscience as it is explicated by the new mechanist philosophy (NMP). One potential barrier is related to the rejection of strong emergentism (SE) by proponents of NMP. In the third section (§III) of this paper, I address why hylomorphic animalism is not a form of strong emergentism. I then draw attention to the similar reasons given by both $H M A$ and NMP for rejecting $S E$ and the Crypto-Cartesian framework that generates it. But this conclusion introduces a new difficulty, for HMA's and NMP's objections to strong emergence seem to apply no less to $T H P$, which maintains that the intellectual powers of any person are immaterial. I take this challenge seriously. In the second article, I address this challenge and other difficulties with the Thomist account of the interaction of noetic and psychosomatic operations.

\section{Aristotelian Hylomorphic Animalism}

Neo-Aristotelian hylomorphism is the view that all natural substances, that is, of concrete dynamic individual wholes, are constituted from two fundamental ontological principles: substantial form and matter. Form and matter are not concrete parts that can be recognized through perceptual understanding. What we intelligently perceive are natural substances and their attributes, not their substantial form and matter. Substantial form and matter are known through an intellectual analysis of the natural substances 
we intelligently perceive; form and matter are the ontological principles that ground and explain the dynamic unity exhibited in composite physical substances. A salient feature of hylomorphism is its contention that form or organization is a fundamental ontological primitive which actualizes and organizes matter; for hylomorphism, there is no actual matter without actual formal organization. The composition of substantial form united to organized matter in every natural substance also grounds each of the substance's organized material attributes. Like the substance itself, the attributes of hylomorphic substances are also composites of form and matter. These attributes can be comprised of a complex multileveled hierarchy of embodied causal powers that are constituted from organized systems and sub-systems with corresponding activities and subactivities. The causal powers of a physical substance's higher-level attributes are constituted from the actual organization of the material potentialities they organize and integrate into the substance's higher-level systems. Because a substance's higher-level systems are composed from the organized materials of the substance's lower-level systems-such as neurophysiological systems constituted from the organization of more basic organic biochemical systems-the causal powers and activities of higher-level attributes do not violate or compete with, but are enabled by and enlist the activities of the lower-level organic, molecular, atomic, and subatomic systems of the substance. Given the plurality of such causal powers, hylomorphism is committed to a form of property, causal, and explanatory pluralism (Jaworski 2016; Oderberg 2007; Koons 2014; Lonergan 1992; Wallace 1996; Feser 2014).

This rough sketch of Aristotelian hylomorphism in general provides the point of departure for hylomorphic animalism, which combines hylomorphism with a version of animalism (Jaworski 2011, chap. 12; Toner 2011; Thornton 2016; Olson Forthcoming). Hylomorphic animalism (HMA) contends that the best way to get a philosophical grip on the nature of psychological powers and their operations is to start with the putative fact that animals (so, not just human animals) are psychosomatic substances with a complex range of integrated biological and psychological attributes. Contemporary versions of animalism start with claims about the animality of humans; 
Aristotelian animalism starts with claims about animals and their hylomorphic constitution before considering the animality specific to human persons. Animalism, here, means that animals are fundamental entities; animals are unified psychosomatic wholes that are not only more than the sum of their parts, the actualization, identity, and subsistence conditions of an animal's material parts are determined by its substantial form. Additionally, hylomorphic animalism, like most other forms of animalism, maintains that the identity conditions of animals are not tied up with the continuity of their psychological, mental, or conscious states and operations, but with the persistence of the animal as a hylomorphically composed organic substance. Indeed, it is the animal qua substance that grounds the complex organization of material attributes that enables the ontogenetic development of psychological powers and their conscious manifestations. $H M A$ distinguishes the persistence of the substance of the animal from the panoply of psychosomatic powers grounded in the substance, and these powers are distinct from the operations or manifestations of these powers.

Hylomorphism in general, and hylomorphic animalism in particular, are neutral with respect to the more contentious claims of Thomas Aquinas and others who maintain that human persons are a different kind of hylomorphic animal, namely one with an immaterial the intellectual soul that grounds its immaterial noetic powers and operations. In other words, THP amplifies and expands upon the more basic and less controversial claims of $H M A$. Before addressing what THP adds to HMA, let us consider in more detail the hylomorphic animalism defended by Aquinas and Thomists, beginning with the way the soul and its psychological powers and operations animate and organize the organic materials that constitute an animal.

For Aquinas's HMA, "The soul is the actuality of an organic body as [this is] what it perfects primarily and proportionately.” (ST I.76.8ad2) ${ }^{1}$ Because

All translations from the works of Thomas Aquinas are my own unless stated otherwise. Since this is not an exegetical study of Aquinas, but a philosophical essay intended for an interdisciplinary audience, my translations focus more on communicating the meaning of the text to a contemporary audience, than on a literal translation of technical Scholastic nomenclature. 
the soul is the animating substantial form that organizes the organic body of the animal,

the whole soul is in each part of the body by totality of perfection and essence, but not by totality of power. For the soul is not in each part of the body with respect to each of its powers; but is in the eye with respect to vision and in the ear with respect to audition, and so forth. Notice, however, that since the soul requires a diversity of parts, it is not related to the whole and to the parts in the same way. The soul is related to the whole primarily and essentially (per se), as the whole is what it primarily and proportionately perfects. By contrast, the soul is related to the parts derivatively (per posterius), as they are ordered to the whole. (ST I.76.8)

Aquinas distinguishes between the soul's perfective actualization of the entire body that thereby constitutes the complete essence or nature of the animal, from the way the soul grounds and enables the embodied powers of the animal. In the latter case, the soul does not animate the entire body, but informs distinct parts or zones of the body with the distinct animation and organization that constitutes the biofunctional parts and psychosomatic powers of the animal, endowing it with psychosomatic potencies for psychosomatic operations. ${ }^{2}$ The soul's animating organization of organs enables, for instance, the psychosomatic power of vision (which is constituted from the appropriate organization of the material components of such organs as the eyes, retina, optic nerve, lateral geniculate nucleus, visual cortex, and so forth) in one way that is distinct from the way it animates the bodily organs of the ear, cochlea, auditory cortex, and so forth, which constitute the power of audition. In short, HMA holds that an animal is constituted as a substance by virtue of the soul's abiding organizational animation that pervades the entire organic body. But, the vegetative and sentient psychosomatic powers that are animated and enabled by the soul do not permeate the entire body; rather, they are distributed with respect to the biofunctional parts and organs they uniquely in-form and animate.

2 See Aquinas, ST I.75.3; 76.8; 77.5; 84.6-8; 85.1 89.1; 89.5; I-II.17.7-9; In DA II, lt. 2; SCG II.57; 82; De Pot. 3.9ad22. On biofunctional parts, see Jaworski 2016 chap. 6.4. See Oderberg 2017 for an account of organs abtaining a substantial form. 
Following Avicenna and Albert, Aquinas maintains that humans and other animals possess a number psychosomatic powers owing to their sensory soul. Aquinas distinguishes five external apprehensive senses, four internal apprehensive senses (Gestalt sense, i.e., sensus communis, imagination, estimation, memory), two sensual appetites for hedonic affectivity, motivation, and emotion, and a range of motoric powers (See ST I.78.1-4; De Haan 2014a; De Haan 2014b; Stock 1958). All of these sensory powers and their manifestations are psychosomatically constituted and embodied in the organs they organize. Aquinas, like other medieval Neo-Aristotelians, located the internal sense powers and their functions in the ventricles of the brain. Of course, neurobiology has directed the attention of psychologists and philosophers away from the ventricles in the brain and towards the nervous system, and especially towards the brain's neural and glial cells, assemblies, and systems. Despite such incredible advances in neurobiology and neuropsychology, contentious questions about the localization and distribution of psychological abilities in the brain remains as lively as ever (Anderson 2014).

The psychosomatic powers of enactive sensation, enactive estimative perception and registration, ${ }^{3}$ imagination, memory, and capacities for motivation and executive functions enable animals to intentionalize and interact with information from their environment. ${ }^{4}$ The exercise of these

3 I use "enactive" in the technical sense employed by philosophers and scientists influenced by James Gibson's ecological psychology. Alva Noë states that, "According to the enactive approach, perceptual content becomes available to experience when perceivers have practical mastery of the ways sensory stimulation varies as a result of movement." Noë 2004, 199. The adjective enactive signals the qualification that a certain cognitive operation is inextricably tied to its embodied manifestation and dynamic engagement with objects in the environment. I use "registration" and its cognates in a technical way that captures the wide range of psychological functions Aquinas attributes to the cogitative power in humans and the estimative power in other animals, which intersects nicely with many of the ways that "registration" is used to describe the higher-level psychological abilities of animals by Bermudez 2003; Butterfill and Apperly 2013; De Haan 2014a, 2014b; Hutto 2012.

4 Psychological powers intentionalize information in diverse ways. Intentionality denotes the distinctive way that psychological operations enable the animal to cognize about or have cognitive acts that are directed towards their objects. For instance, memories are about the objects I remember and my desire to eat is directed towards food. 
psychological powers is critical for satisfying the complex biopsychosocial imperatives directed towards the survival and flourishing of animals. Many of the animal's psychological powers not only enable it to intentionalize information but to do so consciously. So, for example, the power of vision enables animals to intentionalize visible information such that they can consciously see visible things in the environment. The animal's ability to consciously see intentionalized visual information is explained in part by the integrated operation of its various psychological powers. When exercised, psychological powers like vision enlist a coordinated manifestation of a complex range of psychosomatic powers or mechanisms that constitute the activity of seeing. All of the psychological activities that an animal performs in its environment are comprised of the organized manifestation of the powers of the animal's biofunctional parts and the surrounding materials in the world. For $H M A$, the animal has the psychological powers and operations it does because its biofunctional parts, like the nervous system, are psychosomatically organized in such a way that the organized manifestation of the powers of these biofunctional parts (in conjunction with any reciprocal powers of surrounding materials in the environment) can be harnessed by the psychosomatic activities of the animal (See Braine 1992; Oderberg 2007; Jaworski 2016). Because the animal's psychological operations-like seeing, hearing, enactive perception and executive registrations-are essentially psychosomatic, there is no dichotomy between consciously seeing and the processes of the nervous system. The animal's operation of consciously seeing is hylomorphically constituted from the organization of the complex hierarchy of biological cum psychological components. The details of the latter story are provided by the empirical research of scientists, which are in turn systematically analyzed and made more ontologically perspicuous by philosophers of the special sciences. While $H M A$ merely aims to provide a general ontological framework for understanding the nature of animals and their powers and operations, the new mechanist philosophy of biology, neuroscience, and psychology provides a lucid philosophical interpretation of these special sciences that can enrich HMA's more general claims about the embodied psychological powers of 
animals. Let us examine briefly the potential resources the new mechanist philosophy of science has for filling in the details left out by the ontological framework of HMA. Elsewhere I have argued for the compatibility of hylomorphism and the new mechanist approach to biology, neuroscience, and psychology; I take this compatibility for granted here.

\section{The New Mechanist Philosophy of Biology, Neuroscience, and Psychology}

The new mechanist philosophy's (NMP) approach to biology, neuroscience, and psychology gradually emerged over the past fifty years from a common set of concerns and interests in philosophy of science. The seminal paper of the new mechanists, "Thinking about Mechanisms," by Peter Machamer, Lindley Darden, and Carl Craver, later known as MDC, begins:

In many fields of science what is taken to be a satisfactory explanation requires providing a description of a mechanism. So it is not surprising that much of the practice of science can be understood in terms of the discovery and description of mechanisms. (MDC 2000, 1) $)^{5}$

NMP distinguishes their account of mechanisms from the austere mechanistic ontologies developed by Descartes, Boyle, and many others since them. NMP is especially interested in the methods and actual practices of scientists searching for biochemical, genetic, neurophysiological, and psychological mechanisms. NMP rejects the forms of theoretical imperialism developed by logical empiricists that aimed to reduce all scientific theories to the laws of theoretical physics. Additionally, unlike historical accounts of mechanisms, new mechanists reject the idea that the mechanisms investigated in the life sciences are machines or are anything like machines. At best, some machines are pale imitations of biological mechanisms, for unlike endogenously active organisms, machines do not build, sustain,

5 See Bechtel 2007; Bechtel and Richardson 2010; Craver and Darden 2013; Craver and Tabery 2016; Glennan 2016; Maley and Piccinini 2017. 
and repair themselves. Furthermore, according to Carl Craver and other proponents of NMP, mechanisms are not essentially (a) deterministic (they are also stochastic), (b) reductionistic (most require multilevel irreducible organization), or (c) localizable (they are highly distributed in the brain) (See Craver 2007; Craver and Darden 2013). NMPs identify four elements that are characteristic of mechanisms.

A mechanism is a structure performing a function in virtue of its component parts, component operations, and their organization. The orchestrated functioning of the mechanism is responsible for one or more phenomena. (Bechtel and Abrahamsen 2005, 423)

Mechanisms are entities and activities organized such that they exhibit the explanandum phenomenon. (Craver 2007, 6)

Let us take note of some obvious points of overlap between hylomorphism and NMP's account of these four elements of mechanisms: phenomenon, component entities, component activities, and organization. ${ }^{6}$

\subsection{The Mechanisms of the New Mechanists}

A phenomenon is variously described as the behavior or the manifestation of a capacity or power of the mechanism taken as a whole. For instance, the mechanism for protein synthesis synthesizes proteins and the mechanism for an action potential generates an action potential. Mechanisms explain how organized component entities and their activities produce, underlie, or maintain some phenomenon. Entities and their causal activities or operations constitute the two kinds of component parts of a mechanism. Mechanisms studied in neuroscience, for example, consist of component entities (like neural membranes, $\mathrm{Ca} 2+$ channels, $\mathrm{Ca} 2+$ ions, intracellular molecules, vesicles containing neurotransmitters) that causally interact with other component entities through diverse causal operations (like opening, diffusing, docking, fusing, phosphorylating, and priming) (Craver 2007, 5;

6 For a comparative study of hylomorphism and the new mechanist philosophy, see De Haan 2017. 
Glennan 2009; Craver and Darden 2013). According to MDC, "Activities are the producers of change. They are constitutive of the transformations that yield new states of affairs or new products. Reference to activities is motivated by ontic, descriptive, and epistemological concerns." (MDC 2000, 4; see Glennan 2009, sec. 5) Significantly, despite the range of views about the nature of causality maintained by different new mechanists,

New mechanists have in general been at pains both (1) to liberate the relevant causal notion from any overly austere view that restricts causation to only a small class of phenomena (such as collisions, attraction/repulsion, or energy conservation), and (2) to distance themselves from the Humean, regularist conception of causation common among logical empiricists. (Craver and Tabery 2016, sec. 2.3)

In short, like Neo-Aristotelian hylomorphism, NMP's account of the causal activities of component entities of mechanisms endorses a kind of property, causal, and explanatory pluralism.

More significant, however, is NMP's realist account of organization as an irreducible ontological and explanatory factor in every mechanism. NMP recognizes that spatial, temporal, and active organization of component entities and their activities taken together constitute a mechanism. Active organization, in particular, is essential, for it enables component entities to make a causal difference to other component entities in the mechanism. "There are no mechanisms without active organization, and no mechanistic explanation is complete or correct if it does not capture correctly the mechanism's active organization." (Craver 2007, 136).

Active organization distinguishes mechanisms from mere aggregates (or heaps) of matter, such as piles of sand. The parts act and interact with one another in such a way that the whole is literally not a mere sum of its parts. Mechanisms are in this sense nonaggregative: the parts of the mechanism are organized in ways that go beyond, e.g., the contribution made by the mass of a grain of sand to the mass of the pile. Mechanisms are not mere sums of properties of their component parts.... (Craver and Darden 2013, 20) 
Like hylomorphism, NMP maintains that organization is an irreducible ontological and explanatory principle that makes a difference with respect to the causal operations of the component entities it organizes. "Organization is the interlevel relation between a mechanism as a whole and its components. Lower-level components are made up into higher-level components by organizing them spatially, temporally, and actively into something greater than a mere sum of the parts.” (Craver 2007, 189). Mechanisms, "by virtue of their organization, are able to do things that their parts cannot do individually. They can respond to inputs that the parts alone cannot detect. They can produce behaviors that their parts alone cannot produce. There are generalizations about causal relevance that are true of mechanisms and false of their parts." (Craver 2007, 227 My emphasis).

Finally, as with hylomorphism, $N M P$ also endorses an antireductionist account of the levels of mechanisms discovered in biology, neuroscience, and psychology. NMP acknowledges the ubiquitous presence of mechanisms throughout the world of living organisms that are constituted from complex hierarchies of levels of organized causal components (Craver and Tabery 2016, sec. 2.4.1). The powers of the higher-level mechanisms, say, the visual system, depend upon the coordinated manifestation of the organized causal powers of lower-level systems that constitute the higher-level mechanisms.

The ubiquity of mechanism dependence is a consequence of the hierarchical organization of mechanical systems and processes, and it explains how productive continuity at lower levels in the mechanistic hierarchy give rise to higher level forms of production. Productive powers of wholes derive from the organization of their parts, and the productive continuity of causal processes derives from productive interactions of parts at various stages in the process. (Glennan 2016, 811)

For instance, the mechanisms that underlie the action potential of a neuron are: organized together spatially, temporally, causally, and hierarchically such that transmitters are released when the axon terminal depolarizes. The voltage-sensitive ion channels are located in the terminal, they span the membrane, and they open to expose a channel. Biochemical cascades in the cytoplasm have 
sequences or cycles of interactions, they are organized in series and in parallel, and their steps have different orders, rates and durations. The components in the mechanism often stand in mechanism/component relations, a species of part-whole relation. As a result the mechanism is hierarchically organized. The behavior of the mechanism as a whole requires the organization of its components. (Craver 2007, 6)

William Bechtel, Craver, and many other new mechanists distinguish between intralevel causal relations and interlevel constitutive relations. Given common contemporary philosophical assumptions that all causation is efficient causation, that cause and effect must be distinct entities, and all causal relationships are contingent and diachronic, they argue that there cannot be any interlevel causal relations between wholes and their parts. Causation concerns the intralevel operations among organized component entities at the same level in a mechanism, which are distinct from each other and are contingently related. It is constitution that captures the kind of synchronic dependency between wholes and their parts, especially those that pertain to the interlevel relations between levels of mechanisms. The behavior of a mechanism, taken as a whole, is thereby constituted from the organization of its component entities and operations, which are not wholly distinct or contingently related as parts of a whole. ${ }^{7}$

The behavior of the whole is dependent on the behavior of the components in such a way that interventions to change the components can change the behavior of the whole and vice versa. While there are not interlevel causal relations in [levels of mechanisms], there are many interlevel relations of dependency, and thereby interlevel relations of regularity and predictability. One can disrupt spatial memory by ablating the hippocampus or knocking out NMDA receptors. (Craver 2007, 183)

Our earlier sketch of HMA's account of embodied psychological powers can accommodate and be enriched by NMP's presentation of mechanisms

In De Haan 2017 I argue that these interlevel constitutive relations of organized components are similar (if not equivalent) to Neo-Aristotelian hylomorphism's account of the union of formal and material causality, which explain the way formally organized material components constitute a whole. 
in biology, neuroscience, and psychology. When an animal exercises its power of vision, this operation enlists the coordinated manifestation of a complex hierarchy of levels of powers nested in psychosomatic systems that range from such neural systems as the eyes, lateral geniculate nucleus, visual cortex, dorsal and ventral visual streams, to various subsystem neural assemblies, down to the myriad extracellular and intracellular neural, glial, and synaptic events that are constituted from the organized interactions of neurotransmitters, ion channels, ions, and so forth, as well as the organelles and various intracellular interactions. Craver and Bechtel provide the following illustration of a complex psychosomatic behavior of a human person, namely, that of Hal playing tennis and the mechanisms for glucose metabolism.

Hal's tennis-playing also alters the behavior of innumerable biochemical pathways and cellular mechanisms that are involved in his tennis playing, both in the short-term and in the long-term. Why did Hal's cells start using more glucose (i.e., binding glucose into molecules of hexosediphosphate)? Because Hal started to play tennis. Similar stories could be told about Hal's respiratory mechanisms, visual system, and many others besides. Changing the behavior of the mechanism as a whole changed the activities of its components. It may be appropriate to say that the components are along for the ride, but if so, this is a different, more active, kind of ride than [when water moves because I move a cup that contains the water]. Hal's glucoregulatory mechanisms are enlisted in the ride. When Hal started to play tennis, the nerve signals to the muscles caused them to metabolize the available ATP to ADP to provide the energy to contract the muscle cells. The increase in ADP made it available as a receptor for phosphates in high-energy bonds in 1,3-diphosphoglycerate produced at the end of the glycolytic process. This allowed a cascade of reactions earlier in the pathway to proceed, eventually allowing a glucose molecule to take up a phosphate from another ATP molecule, initiating the glycolysis of that molecule.

This is the sort of case for which appeal to top-down causation seems most compelling. However, the case can be described without remainder by appeal only to intra-level causes and to constitutive relations: the 'effect' of the tennis match on glucose metabolism is mediated by a mechanism. In outline: Hal's playing tennis is in part constituted by activities at neuromuscular junctions, 
and activities at those junctions cause, in a perfectly straightforward etiological sense, changes in the organization and behavior of cellular mechanisms. Even if this is made possible by the incorporation of complex interactions, including feedback loops, inside the mechanism, there is nothing mysterious about appealing to a change at a higher level to explain a change at a lower level. Once we have described the mechanism mediating the effect, the drive to speak of this as a case of top-down causation vanishes, although such language might be useful as shorthand. As long as an analysis like that offered above is available, there is nothing problematic in so using it. (Craver and Bechtel 2007, 559-60)

Empirical investigations continue to produce more detailed and accurate descriptions and explanations of how these psychological and neurobiological mechanisms and systems are integrated together to constitute the manifestation of the animal's psychosomatic abilities. This empirical task belongs to neuroscience and neuropsychology, not to philosophy. There are, however, a number of philosophical issues to be flagged concerning this proposed union between $H M A$ and $N M P$. The most significant for our purposes concerns NMP's challenge to strong emergentism (SE). ${ }^{8}$

8 Some proponents of NMP integrate the information processing mechanisms postulated by cognitive science into their accounts of the hierarchy of psychological and neurophysiological mechanisms. It is beyond the aims of this paper to address the (in)compatibility of HMA with the surfeit of idealized models of animal behavior from cognitive psychological and cognitive neuroscience. Nonetheless, a few points of clarification are in order. First, unless stated otherwise, this paper does not employ such terms as "cognitive" "cognition"-as they are employed in cognitive science, cognitive psychology, and cognitive neuroscience-to mean computational information processes over causal and/or intentional representations by fully or partially modular "cognitive" components. Rather, I employ "cognition" in much the same way Aquinas uses the term "cognitio," namely, as an analogous term that applies to a range of personal or animal level apprehensive powers and their conscious and intentional operations like vision, tactility, imagination, memory, and understanding. Second, if cognitive science's idealized models are interpreted realistically (and not instrumentally via a Dennett-style intentional stance), then such "cognitive mechanisms" can only be attributed to sub-personal level processes and not to personal level powers and operations for enactive perception or rational and intentional action. I develop this distinction more in the next section. For the relevant debates about cognitive science, see Anderson 2014; Bechtel 2007, 2009; Chemero 2011; Hutto and Myin 2012, 2017; Piccinini and Craver 2011; Ramsey 2007. 


\subsection{The New Mechanists and Strong Emergentism}

$S E$ is a form of irreducible ontological emergentism that is distinct from the less contentious weak emergentism, which often amounts to a form of epistemological emergence (Bedau and Humphreys 2008). SE is motivated by a number of important philosophical arguments, but many proponents of $S E$ also look to empirical work in neuroscience and psychology for scientific support of emergentism, such as purported scientific evidence of top-down causation where irreducible higher-level systems produce effects on lower-level systems. According to $N M P$, a closer examination of the empirical evidence of top-down causation appealed to by $S E$ turns out to rest upon category mistakes and conceptual confusions. This empirical evidence does not substantiate the ambitious metaphysical claims of $S E$ for it can be adequately explained by NMP's account of mechanistically mediated effects. Bechtel and Craver provide a revisionary interpretation of empirically discovered instances of purportedly bottom-up or top-down causation that explains such evidence in terms of their account of intralevel causal relations and interlevel constitutive relations. Bechtel and Craver think there is a great deal of confusion about causality, constitution, and emergence in both philosophical and scientific literature on top-down causation. What scientists are in fact discovering are not top-down causes, but instances of mechanistically mediated effects, which are hybrids of constitutive and causal relations that explain levels of mechanisms (Craver and Bechtel 2007, 547).

The shroud of mystery surrounding interlevel causation arises from the assumption that the interlevel relation in such cases is both constitutive and causal at once. On our view, the interlevel relationship is only constitutive. This hybrid framework provides a way to understand most, if not all, the cases for which appeal to top-down causes seems compelling. There may be cases that cannot be handled by this account, but if there are, those who invoke the notion of top-down causation for them owe us an account of just what is involved.... Although our explication of interlevel causation in terms of mechanistically mediated effects renders reference to top-down causation unproblematic, it does not show that the phenomenon is unimportant. The biological world, and much of the world besides, is populated by multilevel mechanisms. Talk 
of interlevel causation is merely a misleading way to talk about an explanatory interlevel relationship that, upon close inspection, does not involve interlevel causes. (Craver and Bechtel 2007, 562)

They conclude with a challenge to SE's claim that neuroscience provides empirical support for their position. In particular, Bechtel and Craver are suspicious of strong emergentists that look to neuroscience for validation of their view that the ontological emergence of mental properties from the complex organized physical properties of the brain is a kind of brute emergence.

[O]ne who insists that there is no explanation for a nonrelational property of the whole in terms of the properties of its component parts-plus-organization advocates a spooky form of emergence. Indeed, levels of mechanisms are levels of ontic mechanistic explanation. Advocates of the spooky emergence of higher-level properties must have in mind a different sense of "level" altogether. Advocates of spooky emergence cannot therefore appeal to levels of mechanisms to make their view seem familiar and unmysterious. (Craver 2007, 217)

$N M P$ 's challenge to $S E$ says nothing about the independent philosophical arguments for $S E$ and its account of brute emergent laws; what NMP contends is that $S E$ cannot maintain both that there are no mechanistic explanations for its purported mental properties and that there is empirical evidence from neuroscience that supports $S E$. Why does NMP's challenge to $S E$ not threaten our proposed union between $H M A$ and NMP? After all, HMA, like $S E$, maintains that higher-level attributes have irreducible powers that make a difference to the coordinated manifestation of lower-level powers. To see why NMP's challenge does not undermine the proposed union between NMP and $H M A$, we must distinguish $H M A$ from $S E$.

\section{Hylomorphic Animalism and Strong Emergentism}

Many Aristotelian hylomorphists are attracted to scientific and philosophical presentations of emergence and top-down causation, especially because emergentist theories defend a nonreductive view of reality. The temptation to combine hylomorphism and emergentism is understandable as both 
positions endorse irreducible accounts of the mind; however, it is important to realize that not all irreducible theories of mind are created equal. More to the point, many nonreductive theories remain fundamentally incompatible with each other, like hylomorphism with emergentism and its older cousin, interactionist substance dualism. In this section, I draw attention to a few reasons why I think contemporary Aristotelian hylomorphists would be better off, not muddying the waters by associating their causal pluralism of material, formal, efficient, and final causes, with the more restrictive Crypto-Cartesian views about causality that motivate standard accounts of $S E$ and its "spooky" account of top-down causation and other explanatory burdens. ${ }^{9}$

As we have seen, $H M A$ 's Neo-Aristotelian approach to psychological attributes, begins with animals and understands psychological attributes as the attributes of animals. This Neo-Aristotelian approach is radically different from standard accounts of $S E$ in philosophy of mind, which neither approach psychological attributes by starting with animals nor even hold that animals are a fundamental kind of substance in their ontology. $S E$ in philosophy of mind, the kind of emergentism at issue here, contends that irreducible mental properties emerge from physical properties in accordance with brute fundamental laws of emergence. These ontologically emergent mental properties and causal powers are just as fundamental or ontologically irreducible as physical properties. In other words, $S E$ is a kind of dualism. $S E$ is one position among many in contemporary philosophy of mind, which includes other dualisms (like substance dualism, panpsychism, and epiphenomenalism) and physicalist monisms (like eliminative, reductive,

9 See Clayton and Davies 2006; Jaworski 2016; Koons Forthcoming; McLaughlin 1992; O'Connor and Churchill 2009; Rickabaugh Forthcoming; Stump 2012. Of course, downward causation need not be identified with efficient causation. Many Neo-Aristotelians interpret cases of downward causation in terms of formal causality, which does not require the features presumed by standard accounts of (efficient) causation-e.g., that effects are wholly distinct events from their causes, are contingently and diachronically related-which is what renders interlevel causation problematic for explaining part-whole dependencies identified by NMP. Because contemporary philosophers do not understand emergentism or downward causation in terms of formal causality, I think it is more advisable for Neo-Aristotelians to avoid potential equivocations and resist the temptation to run hylomorphism together with emergentism and downward causation. 
and nonreductive physicalism). $S E$ shares with these alternative ontologies of the mind the same Crypto-Cartesian conceptual framework for approaching the mind and psychological attributes. Crypto-Cartesianism denotes a conceptual framework for approaching the mind and body. While Cartesian substance dualism and eliminative materialism defend two radically different ontologies - the former holds the mind is a substance distinct from physical substances, the latter rejects the existence of and theories about mental properties or substances distinct from physical objects-they both share the fundamental assumptions of a Crypto-Cartesian conceptual framework. Crypto-Cartesianism commences with a mental-physical dichotomy and a number of "intuitive" assumptions about mental and physical properties. From this shared starting point, different philosophies of mind undertake their own approach to the Herculean labors of either explaining the compatibility of mental and physical properties or explaining how to eliminate or reduce the mental to the physical.

Emergent property dualists typically defend a version of physical substance monism combined with a property dualism, where the physical substance grounds its physical properties, and the appropriate complex organization of physical properties generates distinct mental properties, like phenomenal conscious experiences, intentionality, beliefs, desires, intentions, and so forth. The less common emergentist position known as emergent substance dualism doubles down and maintains that complex physical substances and properties can produce novel ontologically irreducible substances and properties, like persons and mental properties, respectively. Let us focus on the standard SE's accounts of emergent property dualism.

Proponents of $S E$ maintain that the mental properties emerge from organized complex physical systems and only persist if the underlying physical systems maintain their organized complexity. These novel mental properties are produced by-but not realized in-certain structured or organized properties of a physical system. Emergent properties are products distinct from the organized physical properties that produced them. Depending upon whether the proponent of $S E$ is an eliminativist, reductionist, or nonreductionist about diverse physical entities, the physical systems that 
produce emergent properties might be animals, but they might also be the brains of animals or, more likely, the fundamental (perhaps subatomic) physical particles in the universe. Hence, $S E$ can endorse a version of animalism, but it need not; indeed, some, if not most, strong emergentists would deny animals have mental properties. HMA can countenance a form of hylomorphic emergence or, more traditionally, eduction, but hylomorphic eductionism is fundamentally different from strong emergentism. ${ }^{10}$

$H M A$ plays a different philosophical game insofar as it rejects nearly all the starting points and assumptions of Crypto-Cartesian philosophy of mind. ${ }^{11}$ Indeed, it is misleading to conceptualize HMA's Neo-Aristotelian

10 See Koons 2014; Oderberg 2007; Stump 2012; Lonergan 1992; Decaen 2000; De Haan Forthcoming; Brower 2014.

11 Most philosophers of mind also take for granted that all commonsense or folk psychological discourse about mental properties-with the possible exception of qualia-is theoretical discourse. According to this widespread view, beliefs, desires, intentions, and so forth are unobservable theoretical postulates that provide causal explanations of the observable bare bodily behavior of animals. Neo-Aristotelians reject (1) the theoretical model of mental attributes and folk psychology, (2) the Crypto-Cartesian false dichotomy between empirically observable bodily behavior and unobservable psychological/mental attributes, and (3) the so-called standard theories of mental causation and causal theories human action. See Armstrong and Malcolm 1984; Churchland and Haldane 1988; Hutto 2012; Sellars 1963. For Neo-Aristotelians, the psychological concepts employed in our everyday commonsense discourse about humans and other animals are pre-theoretical. Furthermore, the observable behavior of animals is often psychological behavior, that is, the overt bodily behavior of animal is constituted from the manifestation of their psychological capacities for seeing, hearing, desiring, registering, and being in pain, and such psychological behavior is just as observable as their tracking, fleeing, hiding, and nursing psychological behavior. Additionally, the very meaning of our ordinary psychological concepts are partially constituted from our understanding of the psychological behavior of animals we perceptually experience. This is why certain patterns of psychological behavior provide the paradigmatic form of criterial evidence for the ascription of psychological attributes, even if this criterial evidence is defeasible in light of countervailing evidence. Finally, Neo-Aristotelian's reject the causal monism and Humean assumptions that underwrite the standard causal theories of the mind and human action. Instead, Neo-Aristotelians embrace causal and explanatory pluralism and do not hold that reasons and psychological causes must be distinct existents that are merely contingently related to their effects. These differences, and many others, explain why Neo-Aristotelians that are true to their first principles adopt radically different positions in the philosophy of intentional action, moral psychology, human agency, and the metaphysics of free will. These complex issues, of course, go beyond the scope of this study. See Bennett and Hacker 2003; Hacker 2008; Ryle 2009; Hyman 2015; Lonergan 1992; Jaworski 2016. 
views on rational and other animals as a position within philosophy of mind; rather, it is a philosophy of animal psychology (or, in the human case, a philosophical anthropology). It begins with animals, not minds or the physical. It rejects the Crypto-Cartesian mental-physical dichotomy in favor of its psychosomatic descriptions and explanations of animals and their psychological attributes in terms of animating forms of organized organic matter. A hylomorphically educed substance, like an animal, simply is the irreducible unified whole that is constituted from the organization of its material components; the animal is identified with the form-matter composite substance and its attributes, not with any purported mental or physical properties or physical substance with mental properties. Additionally, for $H M A$, psychological attributes do not emerge from physical attributes; rather, it is the animal-the composite substance of organic matter organized by animating substantial form-that grounds and enables its psychosomatic attributes. The animal's irreducible psychosomatic powers of vision, audition, perceptual registration, memory, emotion, and executive functions are ontologically derived from its substantial form, not from its physical, chemical, or biochemical attributes for these attributes are also ontologically grounded in the substance of the animal. For HMA, the substance is fundamental with respect to its attributes. Nevertheless, $H M A$, like $N M P$, holds that the animal's higher-level attributes, such as its psychological powers, are psychosomatically constituted from the organization of the animal's lower-level attributes, like the brain. And this is why $H M A$, again like $N M P$, rejects $S E$ 's position that higher-level powers are emergent products distinct from the complex organization of lower-level attributes that cause them to exist. Said otherwise, higher-level powers, for $H M A$, are not emergent effects or distinct extrinsic products that are causally produced by the organization of lower-level physical factors; they simply are the irreducible psychosomatic powers composed of organized lower-level attributes. Consequently, $H M A$, unlike $S E$, can endorse $N M P$ 's claim that levels of mechanisms provide constitutive and causal explanations of the irreducible psychological powers and manifestations that enable animals to engage in conscious intentional operations such as seeing, hearing, feeling, 
and perceptually registering objects that afford fleeing from, fighting, or pursuing and consuming.

Eric LaRock has recently articulated an empirically sensitive version of emergent substance dualism that he describes as being an Aristotelian version of strong emergentism (LaRock 2013). This is not the place to examine his view at length, however, it is important to draw attention to a few of the ways LaRock's Aristotelian emergentism is fundamentally incompatible with my Aristotelian and Thomist account of hylomorphic animalism and hylomorphism personalism. For LaRock, the brain generates an irreducible emergent individual agent, which is a conscious mental agent that unifies the mental properties that emerge from distributed neural assemblies in the brain. LaRock suggests that this Aristotelian emergent agent is the "rational, voluntary soul (i.e., emergent agent)" and that it exercises efficient, formal, and final causality through which it is capable of "affecting the matter that generates it.” (LaRock, 388). LaRock's treatment of the irreducible unity of consciousness over distributed neural modalities and agent-directed neural plasticity provides insightful arguments that can, with important modifications, be integrated into HMA and THP.

$H M A$ and THP are both incompatible with the $S E$ conclusions LaRock draws from these arguments. This is because LaRock's Aristotelianism is developed out of the same Crypto-Cartesian framework as other forms of $S E$, where it is the brain that generates the emergent conscious agent and its mental properties, not the hylomorphic animal substance that grounds both its psychosomatic powers and the subpsychological powers of the nervous system that materially constitute and enable these psychological powers. Whereas the soul is the substantial form of the animal for HMA, LaRock identifies the emergent individual agent with the soul and the soul is emergently generated by the brain, whose complex organization is not due to the soul and is sufficient to produce a distinct individual emergent agent, namely, the soul. So far as I can tell, the only significant "Aristotelian" difference between LaRock's view and other forms of emergent substance dualism, is that emergent individuals, for LaRock, exercise not only efficient, but also formal and final causality on the brain, by taking advantage of the 
brain's plasticity and material potentialities. However, LaRock understands all of these forms of mental causation as forms of strong emergentist downward causation, which NMP and HMA reject. For these efficient, formal, and final mental causes are all extrinsic causes with respect to the physical composition and properties of the nervous system. Unlike in $H M A$, LaRock's emergentist mental causes are not immanent efficient, formal, and finally causes that constitute the organization of the nervous system and its properties, they are separate mental properties that exercise extrinsic mental causation on the nervous system that produced the emergent mental substance in the first place.

I draw attention to these points of disagreement between LaRock's Aristotelian version of $S E$ and my own Aristotelian version of $H M A$ to set in relief their radical differences as incompatible ontologies with incompatible approaches to neuroscience and psychology. I am not suggesting I have provided cogent philosophical reasons for rejecting LaRock's philosophical defense of strong emergentism. But insofar as proponents of $S E$, like LaRock, appeal to neuroscience and psychological for empirical evidence of downward causation to bolster their philosophical arguments, then they fall squarely within the sights of NMP's critique. Since $H M A$ rejects this appeal to empirical evidence of downward causation and can endorse NMP's hybrid explanations involving constitutive and causal relations, HMA is not vulnerable to NMP's critique of emergentism.

The concordance of HMA and NMP on the aforementioned topics is made clearer still by introducing a distinction between personal and sub-personal level attributes and connecting it with the homunculus fallacy and what has been variously called Aristotle's principle or the mereological fallacy. ${ }^{12}$ Aristotle's principle draws attention to conceptual confusions and category mistakes that arise from otherwise harmless forms of metonymy and synecdoche. We often speak loosely and say that the eye sees, the intellect understands, or my brain believes, but, as Aristotle notes, strictly speaking

12 See Aristotle, De anima I.4.408b12-15; Aquinas, ST I.75.2ad2; Wittgenstein 2010, §§ 281-284; 357-361; Kenny 1971; Bennett et al. 2007; Bennett and Hacker 2003, 2012; Kenny 2009; De Haan and Meadows 2013; Smit and Hacker 2014. 
it is more accurate to say that it is the human that sees, understands, and believes by harnessing the capacities of the eye, intellect, and central nervous system. Such uses of synecdoche become problematic when one contends that psychological attributes that literally only apply to the animal as a whole, can also be attributed literally to parts of the animal, like its brain. These category mistakes are exacerbated, when psychological attributions to bits of the brain (or to purported cognitive information processing modules realized therein) are claimed to provide more cogent explanations of the sufficient causes of the animal's psychological behavior, than the ordinary ascriptions of psychological attributes to the animal as a whole. In their extended critique of the influence of Crypto-Cartesianism in neuroscience, psychology, and philosophy, Maxwell Bennett and Peter Hacker call the systematic violation of Aristotle's principle the mereological fallacy, because such errors involve mistakenly ascribing psychological attributes to parts of an animal, that can only be ascribed to the animal as a whole.

These category mistakes violate the homunculus fallacy as well insofar as they posit homunculi that are supposed to perform semi-psychological functions (e.g., proto-seeing or proto-rational decisions) that provide explanations of how the human performs full-blown psychological operations (e.g., seeing or rational decisions). The real difficulty here is with the claim that the mystery of how human thinking occurs is explained by positing homunculi in the brain that exercise proto-thinking. Such explanations merely introduce more mysterious processes to explain the less mysterious ones. It is nearly always problematic to suggest that the operations proprietary to a whole can be explained by postulating that the whole's nonaggregative parts perform the same kind of operation-even in a diminished fashion-that is performed by the whole. As Bechtel points out, this is not the view that NMP endorses.

Typically, though, the operations within a mechanism are different from the phenomenon produced by the mechanism. Within a neuron, for example, neurotransmitters perform such operations as diffusing across a synapse and binding to a receptor; but the neuron itself generates action potentials. The point of organizing component parts and operations into a mechanism is to 
accomplish something that cannot be performed by the individual components. Hence, assuming a homunculus with the same capacities as the agent in which it is posited to reside clearly produces no explanatory gain. (Bechtel 2009, 561)

The distinction between personal and sub-personal (or animal and sub-animal) levels of description and explanation, as this distinction is employed by John McDowell and Jennifer Hornsby, adds another layer of clarity by drawing attention to the specific kinds of wholes and parts at issue here, namely, wholes that are human persons or some other kind of animal (Hornsby 2000; McDowell 1994). There are kinds of anticipations, predictions, descriptions, and explanations of the psychological behavior of human persons (and other animals) in terms of reasons, beliefs, intentions, decisions, desires, wishes, emotions-in short, the whole stock of ordinary psychological attributes-that are proprietary with regards to the personal level (or animal level). This distinction does not mean the personal level psychological attributes come unmoored from sub-personal level explanations as is the case with interactionist substance dualism and $S E$. Indeed, like HMA, Hornsby endorses this distinction to "recover a non-dualist anti-physicalistic position. It takes personal-level states and powers to be part of our natural endowment as sentient and rational animals." (Hornsby 2000, 23). Accordingly, this distinction elucidates the diverse but interdependent levels of ontic explanation that allow us to affirm that the hybrid constitutional and causal explanations of sub-personal levels enable the personal-level psychological abilities attributed to the human person, without falling victim to the confusions identified by the homunculus fallacy. Finally, the causal and explanatory pluralism of $H M A$ and NMP not only provide a robust framework for understanding the distinction between personal and sub-personal level attributes, but also illuminate the wide range of sub-personal level attributes that exist-sub-personal level attributes that range from the objects treated in systems neuroscience, to neural assemblies, to individual neural cum glial interactions, to individual synaptic events, inter-/intra-cellular activities and on down to molecular, atomic, and subatomic activities. 


\section{Conclusion}

What do these complex issues have to Thomist hylomorphic personalism? The comparisons of HMA, NMP, and $S E$ in the previous sections were neither intended to be defenses nor refutations of any of these complex positions. My aim was to clarify why the distinct frameworks that drive $S E$ and $H M A$ render these two ontologies fundamentally incompatible, and therefore why $N M P$ 's challenge to $S E$ is not directed at $H M A$, which is compatible with NMP. But what about the more contentious claims of Thomist hylomorphic personalism? How does it fit within the less controversial picture provided by $H M A$ and NMP? What distinguishes its account of the interaction of immaterial intellectual operations with psychosomatic operations from the strong emergentism critiqued by NMP? These questions will be addressed in a second article that builds upon the foundation laid in this article. ${ }^{13}$

\section{References}

\section{Primary Sources}

Aristotle. 1984. De anima. Translated by J. A. Smith. In The Complete Works of Aristotle, edited by Jonathan Barnes. Vol. 1, 641-92. Princeton, NJ: Princeton University Press.

Aquinas, Thomas. Sentencia libri De anima. ed. R.-A. Gauthier, Leonine, vol. 45/1. Rome, 1984.

Aquinas, Thomas. 1949. Quaestiones disputatae de potentia. ed P.M. Pession. In

S. Thomae Aquinatis Quaestiones disputatae. 8th ed. Vol. 2. Turin: Marietti.

Aquinas, Thomas. 1961. Liber de veritate catholicae Fidei contra errores infidelium seu

Summa contra Gentiles, t. 2-3. eds. P. Marc, C. Pera, P. Caramello. Rome: Marietti. Aquinas, Thomas. 1962. Summa theologiae. Rome: Editiones Paulinae.

13 This essay developed out of a paper I presented at an interdisciplinary workshop, "Soul or Brain: What makes us human?" at the Nicolaus Copernicus University in Torun, Poland in October, 2016. I would like to thank the workshop participants for their helpful comments and the organizers for their kindness and generosity. I must also thank Domenic D'Ettore for his feedback on an earlier draft of this essay. My research for this essay has been funded by the Templeton World Charity Foundation's Theology, Philosophy of Religion, and the Sciences project at the University of Cambridge. 


\section{Secondary Sources}

Anderson, Michael L. 2014. After Phrenology: Neural Reuse and the Interactive Brain. MIT Press.

Armstrong, David M., and Norman Malcolm. 1984. Consciousness and Causality: A Debate on the Nature of Mind. Blackwell.

Bechtel, William. 2007. Mental Mechanisms: Philosophical Perspectives on Cognitive Neuroscience. Psychology Press.

Bechtel, William. 2009. “Constructing a Philosophy of Science of Cognitive Science.” Trends in Cognitive Sciences 1 (3): 548-69.

Bechtel, William, and Adele Abrahamsen. 2005. "Explanation: A Mechanist Alternative." Studies in History and Philosophy of Science Part C: Studies in History and Philosophy of Biological and Biomedical Sciences 36 (2): 421-41.

Bechtel, William, and Robert C. Richardson. 2010. Discovering Complexity: Decomposition and Localization as Strategies in Scientific Research. MIT Press.

Bedau, Mark A., and Paul Humphreys. 2008. Emergence: Contemporary Readings in Philosophy and Science. MIT press.

Bennett, M. R., and P. M. S. Hacker. 2003. Philosophical Foundations of Neuroscience. Vol. 79. Malden MA: Blackwell Publishing.

Bennett, M. R., and P. M. S. Hacker. 2012. History of Cognitive Neuroscience. John Wiley \& Sons.

Bennett, Maxwell, Daniel Dennett, Peter Hacker, John Searle, and Daniel N. Robinson. 2007. Neuroscience and Philosophy: Brain, Mind, and Language. Columbia University Press.

Bermudez, Jose Luis. 2003. Thinking Without Words. Vol. 11. Oxford University Press. Braine, David. 1992. The Human Person: Animal and Spirit. University of Notre Dame Press.

Brower, Jeffrey E. 2014. Aquinas's Ontology of the Material World: Change, Hylomorphism, and Material Objects. Oxford University Press.

Butterfill, Stephen A., and Ian A. Apperly. 2013. "How to Construct a Minimal Theory of Mind." Mind and Language 28 (5): 606-637.

Chemero, Anthony. 2011. Radical Embodied Cognitive Science. Bradford.

Churchland, Paul, and John Haldane. 1988. "Folk Psychology and the Explanation of Human Behaviour." Aristotelian Society Supplementary Volume 62 (1): 209-54.

Clayton, Philip, and P. C. W. Davies. 2006. The Re-Emergence of Emergence: The Emergentist Hypothesis From Science to Religion. Oxford University Press.

Craver, Carl F. 2007. Explaining the Brain: Mechanisms and the Mosaic Unity of Neuroscience. Oxford University Press, Clarendon Press. 
Craver, Carl F., and William Bechtel. 2007. “Top-down Causation without Top-down Causes." Biology and Philosophy 22 (4): 547-63.

Craver, Carl F., and Lindley Darden. 2013. In Search of Mechanisms: Discoveries across the Life Sciences. University of Chicago Press.

Craver, Carl, and James Tabery. 2016. “Mechanisms in Science.” In The Stanford Encyclopedia of Philosophy, edited by Edward N. Zalta, Winter 2016. http://plato. stanford.edu/archives/win2016/entries/science-mechanisms/.

De Haan, Daniel D. Forthcoming. “Dator Formarum, Emergentism, or Educed Substantial Forms? Hylomorphic Mixts and Elemental Virtual Presence.”

De Haan, Daniel D. 2014a. "Moral Perception and the Function of the Vis Cogitativa in Thomas Aquinas's Doctrine of Antecedent and Consequent Passions.” Documenti E Studi Sulla Tradizione Filosofica Medievale 25: 289-330.

De Haan, Daniel D. 2014b. "Perception and the Vis Cogitativa: A Thomistic Analysis of Aspectual, Actional, and Affectional Percepts.” American Catholic Philosophical Quarterly 88 (3): 397-437.

De Haan, Daniel D. 2017. "Hylomorphism and the New Mechanist Philosophy in Biology, Neuroscience, and Psychology.” In Neo-Aristotelian Perspectives on Contemporary Science, edited by William M. R. Simpson, Robert C. Koons, and Nicholas J. Teh. Routledge.

De Haan, Daniel D., and Geoffrey A. Meadows. 2013. "Aristotle and the Philosophical Foundations of Neuroscience." Proceedings of the American Catholic Philosophical Association 87: 213-230.

Decaen, Christopher. 2000. “Elemental Virtual Presence in St. Thomas.” The Thomist 64 (2): $271-300$.

Feser, Edward. 2014. Scholastic Metaphysics: A Contemporary Introduction. Editions Scholasticae.

Glennan, Stuart. 2009. “Mechanisms.” In The Oxford Handbook of Causation, edited by Helen Beebee, Christopher Hitchcock, and Peter Menzies, 315-25. OUP.

Glennan, Stuart. 2016. "Mechanisms and Mechanical Philosophy.” In The Oxford Handbook of Philosophy of Science, edited by Paul Humphreys, 796-816. OUP.

Hacker, P. M. S. 2008. Human Nature: The Categorial Framework. Wiley-Blackwell. Hornsby, Jennifer. 2000. “Personal and Sub-Personal: A Defence of Dennett's Early Distinction." Philosophical Explorations 3 (1): 6-24.

Humphreys, Paul. 2016. Emergence. Oxford University Press.

Hutto, Daniel D. 2012. Folk Psychological Narratives: The Sociocultural Basis of Understanding Reasons. Bradford.

Hutto, Daniel D., and Erik Myin. 2012. Radicalizing Enactivism: Basic Minds Without Content. MIT Press. 
Hutto, Daniel D., and Erik Myin. 2017. Evolving Enactivism: Basic Minds Meet Content. MIT Press.

Hyman, John. 2015. Action, Knowledge, and Will. Oxford University Press.

Jaworski, William. 2011. Philosophy of Mind: A Comprehensive Introduction. Wiley-Blackwell.

Jaworski, William. 2016. Structure and the Metaphysics of Mind: How Hylomorphism Solves the Mind-Body Problem. Oxford University Press.

Kenny, Anthony. 1971. “The Homunculus Fallacy.” In Interpretations of Life and Mind, edited by Marjorie Glicksman Grene and Ilya Prigogine, 155-165. New York: Humanities Press.

Kenny, Anthony. 2009. “Cognitive Scientism.” In Wittgenstein and Analytic Philosophy: Essays for P. M. S. Hacker, edited by Hans-Johann Glock and John Hyman, 250-62. OUP.

Koons, Robert. Forthcoming. “Against Emergent Individualism.” In Blackwell Companion to Dualism, edited by Jonathan Loose, Angus Menuge, and J. P. Moreland. Wiley-Blackwell.

Koons, Robert. 2014. “Staunch vs. Faint-Hearted Hylomorphism.” Res Philosophica 91 (2): 151-77.

LaRock, Eric. 2013. “Aristotle and Agent-Directed Neuroplasticity.” International Philosophical Quarterly 53 (4): 385-408.

Lonergan, Bernard. 1992. Insight: A Study of Human Understanding. University of Toronto Press.

Machamer, Peter K., Lindley Darden, and Carl F. Craver. 2000. “Thinking about Mechanisms.” Philosophy of Science 67 (1): 1-25.

Maley, Cory, and Gualtiero Piccinini. 2017. "A Unified Mechanistic Account of Teleological Functions for Psychology and Neuroscience.” In Explanation and Integration in Mind and Brain Science, edited by David Kaplan. OUP.

McDowell, John. 1994. “The Content of Perceptual Experience.” The Philosophical Quarterly 44 (175): 190-205.

McLaughlin, Brian P. 1992. “The Rise and Fall of British Emergentism.” In Emergence or Reduction?: Prospects for Nonreductive Physicalism, edited by Ansgar Beckermann, Hans Flohr, and Jaegwon Kim. De Gruyter.

Noë, Alva. 2004. Action in Perception. MIT press.

O’Connor, Timothy, and John Churchill. 2009. "Nonreductive Physicalism or Emergent Dualism : The Argument from Mental Causation.” In The Waning of Materialism: New Essays, edited by Robert C. Koons and George Bealer. Oxford University Press. O’Connor, Timothy, and Hong Yu Wong. 2015. “Emergent Properties.” In The Stanford Encyclopedia of Philosophy, edited by Edward N. Zalta, Summer 2015. Metaphysics 
Research Lab, Stanford University. https://plato.stanford.edu/archives/sum2015/ entries/properties-emergent/.

Oderberg, David S. 2007. Real Essentialism. Routledge.

Oderberg, David S. 2017. “The Great Unifier: Form and the Unity of the Organism.” In Neo-Aristotelian Perspectives on Contemporary Science, edited by William M. R. Simpson, Robert C. Koons, and Nicholas J. Teh. Routledge.

Olson, Eric T. Forthcoming. “For Animalism.” In The Blackwell Companion to Substance Dualism, edited by Jonathan Loose, Angus Menuge, and J. P. Moreland. Wiley-Blackwell.

Piccinini, Gualtiero, and Carl Craver. 2011. “Integrating Psychology and Neuroscience: Functional Analyses as Mechanism Sketches.” Synthese 183 (3): 283-311.

Ramsey, William M. 2007. Representation Reconsidered. Cambridge University Press. Rickabaugh, Brandon. Forthcoming. “Against Emergent Dualism.” In The Blackwell Companion to Substance Dualism, edited by Jonathan Loose, Angus Menuge, and J. P. Moreland. Wiley-Blackwell.

Ryle, Gilbert. 2009. The Concept of Mind: 60th Anniversary Edition. Routledge.

Sellars, Wilfrid S. 1963. "Empiricism and the Philosophy of Mind.” In Science, Perception and Reality, 127-96. Routledge \& Kegan Paul.

Smit, Harry, and Peter M. S. Hacker. 2014. "Seven Misconceptions About the Mereological Fallacy: A Compilation for the Perplexed.” Erkenntnis 79 (5): 1077-1097.

Stock, Michael. 1958. "Sense Consciousness According to St. Thomas." The Thomist 21 (n/a): 415-86.

Stump, Eleonore. 2012. "Emergence, Causal Powers, and Aristotelianism in Metaphysics." In Powers and Capacities in Philosophy: The New Aristotelianism, edited by Ruth Groff and John Greco, 48-68. Routledge.

Thornton, Allison Krile. 2016. “Varieties of Animalism.” Philosophy Compass 11 (9): 515-26.

Toner, Patrick. 2011. “Hylemorphic Animalism.” Philosophical Studies 155 (1): 65-81. Wallace, William A. 1996. The Modeling of Nature: Philosophy of Science and Philosophy of Nature in Synthesis. CUA Press.

Wittgenstein, Ludwig. 2010. Philosophical Investigations. John Wiley \& Sons. 